\title{
UNA VIRGEN DE BELÉN ATRIBUIDA AL PINTOR DOMINGO MARTÍNEZ
}

\author{
A VIRGIN OF BETHLEHEM ATTRIBUTED TO THE \\ PAINTER DOMINGO MARTÍNEZ
}

\author{
José RodA PeÑa \\ Universidad de Sevilla. España \\ ORCID: 0000-0002-4141-1178 \\ roda@us.es
}

\begin{abstract}
En este artículo estudiamos las mandas artísticas incluidas en su testamento por el abogado de la Real Audiencia de Sevilla Juan Jacobo Fernández Soriano en 1769, entre las cuales hemos localizado un lienzo de la Virgen de Belén, legado al extinguido convento de religiosas agustinas de Nuestra Señora de la Paz, que se atribuye por primera vez al pintor sevillano Domingo Martínez (1688-1749).

Palabras claves: Domingo Martínez; pintura sevillana; siglo XVIII; legados artísticos; convento de Nuestra Señora de la Paz.
\end{abstract}

In this paper we study the artistic dispositions included in his will by the lawer of the Royal Court of Seville Juan Jacobo Fernández Soriano in 1769, among wich we have located a canvas of the Virgin of Bethlehem, bequeathed to the extinct Convent of Our Lady of Peace, of Augustinian nuns, which is attributed for first time to the sevillian painter Domingo Martínez (1688-1749).

Keywords: Domingo Martínez; Sevillian painting; $18^{\text {th }}$ century; astistic legacies; Our Lady of Peace Convent.

Recién traspasado el umbral de la iglesia del extinguido convento de religiosas agustinas de Nuestra Señora de la $\mathrm{Paz}^{1}$, situada en la calle Bustos Tavera de Sevilla y convertida desde 1936 en sede canónica de la cofradía penitencial de la Sagrada Mortaja -que la disfruta en propiedad desde el 14 de diciembre de 1967-, nos encontraremos a nuestra izquierda con un modesto retablo de finales del siglo

${ }^{1}$ Sobre este convento, fundado en 1571 por el racionero de la catedral de Sevilla Andrés de Segura y exclaustrado en 1837, puede consultarse lo publicado por LLORDÉN, Andrés: Apuntes históricos de los conventos sevillanos de religiosas agustinas. El Escorial, 1944, pp. 17-27; y FRAGA IRIBARNE, María Luisa: Conventos femeninos desaparecidos. Arquitectura religiosa perdida durante el siglo XIX en Sevilla. Sevilla, 1993, pp. 65-75. 
XVIII (Figura 1), de transición al neoclasicismo, cuyo cuerpo principal en su calle central está presidido por un lienzo de mediano formato de la Virgen de Belén $(90$ x $67 \mathrm{~cm})$, que nos parece obra segura e inédita hasta el presente del pintor Domingo Martínez. Hemos podido documentar que dicha pintura forma parte de un legado testamentario ofrecido a este cenobio y a otras instituciones religiosas de la ciudad por el licenciado Juan Jacobo Fernández Soriano, abogado de la Real Audiencia de Sevilla.

En efecto, este último, siendo vecino de la calle Triperas -actual Velázquezy por consiguiente feligrés de la collación de Santa María Magdalena, compareció ante el escribano público Blas de la Vega y Contreras el 24 de agosto de 1769 para protocolizar sus últimas voluntades, "estando con salud aunque con algunos achaques havituales y en todo mi acuerdo, juicio, y entendimiento natural" 2 . Allí confiesa ser natural de Sevilla e hijo legítimo del matrimonio formado por Bartolomé Fernández Soriano, nacido en Higuera de la Sierra, y de la sevillana Catalina Díaz Sánchez, ambos difuntos. Esta ascendencia higuereña lo convierte en pariente, entiendo que muy posiblemente primo hermano, del pintor murillesco Juan Ruiz Soriano (c. 1690/3-1763), que también vino al mundo en esta villa de la serranía onubense ${ }^{3}$.

Pidió amortajarse Juan Jacobo con el hábito de la Santísima Trinidad y ser enterrado en la bóveda de la capilla del sagrario de la parroquia de la Magdalena, de cuya hermandad sacramental era cofrade y elegido por dos veces oficial de su mesa de gobierno ${ }^{4}$. Declara no haber contraído nunca matrimonio, pero en cambio sí había criado en su casa y compañía a dos hijas naturales, Juana y Vicenta Fernández Soriano, que siendo todavía niñas ingresaron en el convento de agustinas de Nuestra Señora de la Paz, "costeándoles todo quanto fue necesario para

2 AHPS (Archivo Histórico Provincial de Sevilla), Protocolos Notariales, leg. 10360, f. $212 \mathrm{r}$.

${ }^{3}$ Juan Ruiz Soriano fue hijo de Juan Fernández Soriano - con toda probabilidad hermano de Bartolomé, el padre de este Juan Jacobo Fernández Soriano de quien nos estamos ocupando-y de Juana Domínguez. Según Ceán, se formó artísticamente en Sevilla en el obrador de su paisano y primo Alonso Miguel de Tovar (1678-1758). CEÁN BERMÚDEZ, Juan Agustín: Diccionario histórico de los más ilustres profesores de las Bellas Artes en España. T. IV. Madrid, 1800, p. 287. Otro Fernández Soriano, de nombre José -hermano posiblemente de los anteriores Bartolomé y Juan-, fue el sacerdote y mayordomo de fábrica de Higuera de la Sierra que en 1735 promovió la inminente construcción del nuevo templo parroquial de esta localidad. Cfr. CARRASCO TERRIZA, Manuel Jesús: "La parroquia de San Sebastián de Higuera de la Sierra", en XXII Jornadas de Patrimonio de la Comarca de la Sierra. Huelva, 2010, p. 39.

${ }^{4}$ Efectivamente, Juan Jacobo Fernández Soriano fue designado como alcalde de la hermandad sacramental de la Magdalena en 1757 y 1767. 
sus ábitos y profesión" su custodia, desde pequeño, a Salvador Damas -"mudo, manco de la mano derecha, e inosente"-, hijo legítimo de su sobrino Juan Damas ${ }^{6}$. Pues bien, a las primeras les legó 200 ducados anuales y al segundo otros 250 para asegurar en el futuro su sustento y vestuario, extraídos de los réditos de un capital colocado a interés. Deja establecido que cuando falleciese una de sus hijas monjas, la otra seguiría recibiendo la totalidad de la suma prenotada, y llegada la muerte de ambas religiosas, de aquella renta se habrían de entregar 1.500 pesos a "mi" cofradía del Santísimo Sacramento y 1.000 más a la "Hermandad de mi Señora del Amparo", radicada asimismo en la parroquia de la Magdalena, para que sus oficiales los pudiesen aplicar en el culto de sus respectivos titulares?.

Interesan particularmente a nuestro propósito las tres cláusulas mediante las que Juan Jacobo Fernández Soriano dona en su testamento una serie de obras artísticas de las que era propietario y que debieron de tener para él una preeminente significación devocional. En primer lugar, manda "una lámina de Nuestra Señora de Velén, con sus coronas de plata, y otra con el título de Pastora al dicho combento de religiosas de Nuestra Señora Santa María de la Paz, para que se coloquen a dispozición de las referidas $\mathrm{D}^{\mathrm{a}}$ Juana y $\mathrm{D}^{\mathrm{a}}$ Vizenta Fernández Soriano, o qualquiera de las dos, y en caso de haver fallecido a dispozición de la señora Abadesa, sin que se puedan vender". A continuación, lega "una hechura de Señor San Joseph mui hermosa, al combento de Señor San Leandro de esta ciudad para que se coloque a dispozición de $\mathrm{D}^{\mathrm{a}}$ Francisca de Paula Aponte, sin que se pueda enajenar". Y para terminar, asigna "una Ymagen de Jesuchrispto nuestro bien, difunto en la Cruz que es de marfil, con su peana mui desente a la dicha Hermandad del Santísimo de la dicha mi Parroquia, para que se coloque en el altar nuevo de Ánima"s.

Después se insertan otras estipulaciones interesantes, como el hecho de dejar a sus pasantes Lorenzo de Escobar y Sebastián Rodríguez sendos juegos de libros, de entre los muchos de ciencias jurídicas que atesoraba en su nutrida biblioteca. También manifiesta poseer un reloj de oro de procedencia londinense, que había adquirido por 6.000 reales, así como un par de hebillas, de ese mismo metal precioso. Por último, nombró como albaceas testamentarios a los dos curas de la parroquia de Santa María Magdalena, Antonio González Cantero e Ignacio

${ }^{5}$ AHPS, Protocolos Notariales, leg. 10360, ff. 212v-213r. En descargo de su conciencia, confesaba Juan Jacobo respecto a estas hijas suyas, que "por ser su madre muger honrada y mosa en toda libertad, se puso con su mismo nombre y apellido en las partidas del Baptismo quando se baptisaron, como si fuera mi muger, declárolo para que así conste".

${ }^{6}$ Ibidem, f. 213r. Juan Damas era hijo de María Fernández Soriano, hermana del testador.

${ }^{7}$ Ibid., f. $213 \mathrm{v}$.

${ }^{8}$ Ibid., f. 214 r.

LABORATORIO DE ARTE 31 (2019), pp. 373-386, ISSN 1130-5762 e-ISSN 2253-8305 - DOI http://dx.doi.org/10.12795/LA.2019.i31.21 
de Arteaga, y por legítimo y universal heredero de sus bienes a su ya mencionado sobrino Juan Damas, y en caso de que este hubiese fallecido, a su mujer e hijos ${ }^{9}$.

En las semanas siguientes, Juan Jacobo Fernández Soriano otorgó hasta seis codicilos que modificaban o ampliaban algunas de las anteriores disposiciones testamentarias ${ }^{10}$. Así, por ejemplo, en el del 1 de septiembre, ordenó que con el dinero sobrante de los réditos anuales, se dijeran tres misas, "una en el altar del Santíssimo Sacramento de dicha su Parroquia, otra en el de Nuestra Señora del Amparo, y la otra en el del Patriarca Señor San Joseph zita en su Capilla calle Manteros, y lo restante se dé de limosna [a los pobres] como está prevenido". Esas mismas cuatro partes habrían de distribuirse el remanente del peculio que pudiera quedar tras cumplirse las instrucciones post mortem del interfecto y la subsiguiente venta y remate de sus pertenencias ${ }^{11}$. El 18 de octubre, Fernández Soriano precisó que de las 1.000 misas rezadas que habrían de aplicarse por su alma, las de sus padres, hermanas y otros allegados, al menos 200 se celebrarían en el convento de los trinitarios descalzos ${ }^{12}$. Un postrer gesto de fineza lo tendría con quien había sido su confesor durante muchos años, el ya citado presbítero Ignacio de Arteaga, uno de sus albaceas, a quien deja el 22 de diciembre "un cubierto de tenedor y cuchara y cuchillo de plata que tenía de su uso con su nombre, mui bueno, un juego de tasas bueno que le regaló la señora Rexenta -la esposa del regente de la Real Audiencia de Sevilla-; y también un juego de platos que le avía regalado D. Miguel del Castillo"13. A los cinco días de este último

\footnotetext{
${ }^{9}$ Ibid., ff. $214 \mathrm{v}-215 \mathrm{r}$.
}

${ }^{10}$ Codicilos otorgados por Juan Jacobo Fernández Soriano ante el escribano público Blas de la Vega y Contreras el 1 de septiembre, 18 de octubre, 29 de noviembre y los días 6 , 15 y 22 de diciembre de 1769. AHPS, Protocolos Notariales, leg. 10360, ff. 218, 231, 256, 258, 291 y 294.

${ }^{11}$ AHPS, Protocolos Notariales, leg. 10360, f. 218v. “...y el sobrante se hagan quatro partes, la una para el Santíssimo Sacramento de la citada su Parroquia, para que se hagan obsequios a su Magestad y por las Ánimas del Purgatorio; la otra a la Señora del Amparo por las almas de sus devotos; y la otra al Señor San Joseph en dicha su Capilla por las de sus devotos; y la última limosna a pobres como está dispuesto". Consta que esa cantidad restante fue de 9.000 reales, repartiéndose a cada una de las partes 2.250. Por parte de la hermandad sacramental de la Magdalena recibió tal suma, el 11 de marzo de 1772, su alcalde el licenciado Feliciano Manuel de Arroyal, abogado y relator de la Real Audiencia de Sevilla; ese mismo día, por la de la hermandad de Nuestra Señora del Amparo, su mayordomo Manuel Sánchez de Herrera; y el 10 de marzo, por la de la hermandad de maestros carpinteros de San José, su mayordomo Pedro Galochas. La noticia referida a la corporación eucarística se conserva en el AHSSMMS (Archivo de la hermandad sacramental de Santa María Magdalena de Sevilla), caja 5, lib. 9, Libro de Actas 1757-1797, cabildo de hacienda de 2 de abril de 1772, f. 203.

${ }_{12}$ AHPS, Protocolos Notariales, leg. 10360, f. 231.

${ }_{13}$ Ibidem, f. 258v. 
otorgamiento, el 27 de diciembre de 1769, era enterrado el cadáver de Juan Jacobo Fernández Soriano, tal como era su deseo, en la capilla sacramental de la Magdalena ${ }^{14}$, oficiándose solemnes honras fúnebres por su alma tres días después, en el citado templo ${ }^{15}$.

Sus albaceas actuaron con la mayor diligencia, pues a los dos días del sepelio, los aludidos sacerdotes elaboraron el inventario de sus bienes ${ }^{16}$ y dieron cuenta del cumplimiento de las dos primeras mandas que ocupan nuestra atención. De esta manera, el 29 de diciembre suscribieron carta de pago ante el escribano público José González Bejarano por la cual Antonia de Miranda, Antonia de Godoy y Francisca Abelló, como abadesa y claveras del convento de Nuestra Señora Santa María de la Paz de Sevilla, ratificaban que el finado había dispuesto que se adjudicaran "a D Juana y Doña Vicenta Fernández Soriano sus hixas relixiosas profesas en el dicho convento para adorno de sus seldas un quadro pintura de $\mathrm{N}$. S. de Belem con el Niño con coronas de plata y dos cornucopias de metal puestas en la moldura que es de madera dorada con una corona de madera dorada y enbutida de christales, todo puesto en un citial de madera dorado su gotera con campanillas, y otro lienso de la Pastora con moldura dorada y de color cuias alaxas permaneciesen en poder de las suso dichas hasta la muerte de ambas, y entonces subcediese en ellas este convento quien las colocase en la parte que tuviese por combeniente prohiviendo que en ningún tiempo ni sus hixas ni el dicho convento las pudiesen dar, vender ni enaxenar porque han de permanecer siempre en este convento", dándose las religiosas agustinas por entregadas de tales prendas ${ }^{17}$.

${ }^{14}$ APSMMS (Archivo de la parroquia de Santa María Magdalena de Sevilla), Libro $7^{\circ}$ de Defunciones 1764-1774, f. 119v. "En veinte y siete días del mes de diziembre de mil setecientos sesenta y nueve años se enterró en la capilla del Santísimo Sacramento de esta Yglesia Parroquial de Señora Santa María Magdalena de Sevilla el cuerpo cadáver del Licdo. D. Juan Jacobo Fernández Soriano de estado soltero; testó ante Blas de la Vega y Contreras escribano público del número de esta ciudad en veinte y quatro días del mes de agosto próximo pasado de este dicho año y en dies y ocho del mes de octuvre de dicho año otorgó codicilo ante el mismo escribano dexando por sus alvazeas en uno y otro a los señores curas de esta dicha Yglesia, D. Antonio González Cantero y D. Ygnacio de Arteaga. Vivía calle Triperas".

${ }^{15}$ Ibidem, f. 120r. "En treinta días del mes de diziembre de mil setecientos sesenta y nueve años se celevraron honras en esta Yglesia Parroquial de Santa María Magdalena de Sevilla por el ánima de D. Juan Fernández Soriano".

16 AHPS, Protocolos Notariales, leg. 10360, ff. 300r-302v y 305r-306v. Las obras artísticas que nos interesan se reseñan en el f. 300: "Primeramente una Lámina con moldura y corona dorada de Ntra. Señora de Belén, con su vidriera y con sus coronas de plata la Virgen y el Niño. Ytt. un lienso de la abocazión de Ntra. Señora la Pastora con su moldura dorada y pintada... Ytt. un Crucifixo de marfil con su corona y potencias de plata. Ytt. una ymajen de escultura de San Joseph con vara y corona de plata”.

${ }_{17}$ AHPS, Protocolos Notariales, leg. 14162, f. 727. 
Aquel mismo día, y ante el escribano público Blas de la Vega y Contreras, la abadesa Francisca Rita de Espinosa Núñez de Prado y claveras del convento hispalense de San Leandro, como el anterior de religiosas agustinas, también otorgaron carta de pago de haber recibido "una Ymagen de bulto de tres quartas poco más de alto [unos $63 \mathrm{~cm}$ ] del Patriarcha Señor San Joseph, con su vara y diadema de plata, y el Niño con su coronita de lo mismo, cuia Ymagen mandó a este nuestro convento D. Juan Jacobo Fernández Soriano, Abogado que fue de la Real Audiencia desta ciudad, de quien son y quedaron albaseas testamentarios los expresados señores curas, cuia Ymagen mandó con la qualidad de que se aya de colocar al adbitrio de $\mathrm{D}^{\mathrm{a}}$ Francisca de Paula Aponte Sánchez y de que no se pudiese enaxenar deste convento" $" 18$.

La tercera de las mandas artísticas se vio cumplida el 4 de enero de 1770 , cuando José Adrián Leal, mayordomo de la hermandad sacramental de la parroquia de la Magdalena firmó recibo de habérsele dado "una Ymagen de Jesuchristo nuestro bien defunto en la Cruz, que es de marfil" 19 .

Pues bien, nada sabemos del paradero actual del lienzo de la Divina Pastora que Fernández Soriano transfirió, en primera instancia, a sus hijas religiosas profesas en el convento de Nuestra Señora de la Paz, como tampoco del grupo escultórico de San José con el Niño Jesús cuyas receptoras fueron las monjas agustinas de San Leandro, ni del Cristo muerto de marfil que debía lucir en el nuevo altar de las ánimas benditas del purgatorio de la hermandad sacramental de la Magdalena ${ }^{20}$. En cambio, tal como anunciábamos al comienzo de estas líneas, sí ha llegado hasta nosotros una pintura de Nuestra Señora de Belén, entronizada en el retablo dispuesto junto a la puerta de entrada de la iglesia del antiguo convento de la Paz (Figura 2). Su identificación con la que Juan Jacobo Fernández Soriano legara a esta extinta clausura no ofrece ningún género de dudas, como lo aseguran tanto la continuidad histórica de su advocación mariana y particular

18 AHPS, Protocolos Notariales, leg. 10360, f. 297. Francisca de Paula Aponte Sánchez era la esposa del V marqués de Carrión de los Céspedes, José Manuel de Céspedes López-Pintado.

19 AHSSMMS, caja 5, lib. 9, Libro de Actas 1757-1797, cabildo de hacienda de 11 de marzo de 1770 , ff. $182 \mathrm{v}-185 \mathrm{r}$.

${ }^{20}$ Quizás ese Crucificado pueda identificarse con el que aparece registrado en un inventario sin fechar, pero confeccionado durante la primera mitad del siglo XIX, donde figura como "Otra [efigie] de N. S. Jesucristo Crusificado, de marfil, con su cruz enchapada de caova, y peana dorada”. AHSSMMS, caja 53, carpeta 906, Inventario del siglo XIX, s.f. Por otra parte, la hermandad sacramental de Santa María Magdalena posee un antiguo Crucificado de marfil expirante -no difunto, como indica la cláusula testamentaria-, de muy pequeño formato, que fue incorporado en 1954 a la cruz de guía que fue labrada en plata de ley por el orfebre Fernando Cruz Suárez, aprovechando como asta el vástago del guión sacramental. 
iconografía, como las coronas de plata a las que alude la documentación original y que siguen ostentando sobre sus cabezas la Virgen y el Niño Jesús.

Desde su llegada, esta representación pictórica debió de ser especialmente apreciada y venerada, primero por las propias herederas del testador -una de las cuales la conservó en vida en su propia celda-, y después por toda la comunidad de religiosas agustinas, según parece indicarlo el hecho de que al finalizar la centuria dieciochesca se le construyera ${ }^{21}$, entendemos que expresamente, un retablo que presidiría a partir de entonces, ocupando el espacio central y privilegiado de su cuerpo principal, articulado por cuatro columnas corintias, quedando el cuadro flanqueado en las entrecalles laterales por los relieves emparejados de los emblemas lauretanos de la Palmera, el Cedro, la Fuente y el Pozo, mientras que el ático de este elegante dispositivo arquitectónico lignario, jaspeado y dorado, aparece regido visualmente por una discreta pintura del Martirio de San Pedro de Arbués.

Respecto a la propia Virgen de Belén (Figura 3), se trata de un óleo sobre lienzo que apenas ha merecido alguna ligera mención por parte de la historiografía artística local, desde Gestoso, que calibró su "regular mérito"22, hasta Martínez Alcalde, que lo tildó de "hermoso y atractivo", recordándole "los tipos usados por el pintor Juan de Espinal" 23 . En realidad, su factura, de notable calidad, la vinculamos al maestro de este último, Domingo Martínez (1688-1749) ${ }^{24}$, como lo predican las características de su estilo, dibujo, composición y colorido, además de las fisonomías de María y del pequeño Jesús, perfectamente reconocibles en otras obras autógrafas de este artífice sevillano, que sin duda comandó el panorama pictórico local durante la primera mitad del siglo XVIII ${ }^{25}$.

${ }^{21}$ González de León, refiriéndose al conjunto de retablos de esta iglesia, nos dirá que "todos los altares que hay en ella son muy modernos, arregladitos al gusto del fin del siglo anterior, y muy bien jaspeados y dorados, por lo que la Iglesia presenta un aspecto risueño y vistoso". GONZÁLEZ DE LEÓN, Félix: Noticia artística, histórica y curiosa de todos los edificios públicos, sagrados y profanos de esta Muy Noble, Muy Leal, Muy Heroica e Invicta Ciudad de Sevilla, y de muchas casas particulares. Sevilla, 1844, p. 454.

${ }^{22}$ GESTOSO Y PÉREZ, José: Sevilla Monumental y Artística. T. III. Sevilla, 1892, p. 311.

${ }^{23}$ MARTÍNEZ ALCALDE, Juan: Sevilla Mariana. Repertorio iconográfico. Sevilla, 1997, pp. 73-74.

${ }^{24}$ Agradezco, en este sentido, los comentarios y valoraciones que esta atribución les ha merecido a los profesores Enrique Valdivieso y Alfonso Pleguezuelo.

${ }^{25}$ Las referencias bibliográficas fundamentales sobre Domingo Martínez las ofrecen SORO CAÑAS, Salud: Domingo Martínez. Sevilla, 1982; ARANDA BERNAL, Ana María: "La biblioteca de Domingo Martinez. El saber de un pintor sevillano del siglo XVIII", Atrio, 6, 1993, pp. 68-69; VALDIVIESO, Enrique: Historia de la Pintura Sevillana. Siglos XIII al XX. Sevilla, 2002, pp. 319-332; VALDIVIESO, Enrique: Pintura Barroca Sevillana. Sevilla, 2003, pp. 524-545; PLEGUEZUELO, Alfonso y VALDIVIESO, Enrique 
La Virgen, tocada su cabeza con un velo marfileño y vestida con los colores concepcionistas azul -el manto-y rosa-la túnica-, está captada de medio cuerpo ante un fondo neutro, mirando francamente al espectador, al que ofrece una delicada sonrisa, como también lo hace el Niño Jesús (Figura 4), a quien sujeta entre sus manos mientras envuelve sus caderas con un blanco pañal, mostrando la criatura una grácil y dinámica actitud corporal, al rotar el torso y sus brazos hacia la diestra, en dirección a su madre, al tiempo que posa su rodilla derecha sobre un cojín con borlón y bascula en diagonal la pierna contraria, apoyando el pie en una base pétrea. De los ángulos superiores del lienzo emergen unas cabezas aladas de querubes, una a nuestra izquierda y dos a la derecha. El esquema compositivo del grupo principal evoca, aun con visibles variantes, el de la Virgen con el Niño plasmado por Domingo Martínez en el dibujo a lápiz negro que se conserva en la Kunsthalle de Hamburgo ${ }^{26}$ y en el lienzo del mismo tema del Museo Diocesano de Zamora ${ }^{27}$, y a la postre, no deja de ser sino una creativa reinterpretación de los prestigiosos modelos proporcionados por Murillo en sus Virgenes con el Niño (c. 1655-1655) de la Galleria Palatina del Palazzo Pitti de Florencia (c. 16501655); de la Homeland Foundation de Amenia, Nueva York (c. 1675) o de la Wallace Collection de Londres (c. 1675)28, entre algunas más.

Es evidente que en esta obra, como en tantas otras de Martínez, late con fuerza la impronta murillesca, aunque dotándola de una indiscutible personalidad propia. La paleta cromática empleada, de suaves tonalidades, delata tempranos efluvios de influjo rococó, que comulgan perfectamente con la abundante presencia de rocallas en la decoración de las coronas argénteas que ciñen las testas de la Virgen y el Niño Jesús; estas preseas debieron de embutirse unos años después de la ejecución del cuadro, como lo delata su diseño y el hecho de que en la tela aún se distingan con claridad las rutilantes estrellas pintadas que circundan la cabeza de María. Todas estas particularidades concuerdan con el

(coms.): Domingo Martínez en la estela de Murillo. Sevilla, 2004; FERNÁNDEZ LÓPEZ, José: "Domingo Martínez y Juan de Espinal: nuevas atribuciones de pinturas de la escuela sevillana del siglo XVIII", Laboratorio de Arte, 20, 2007, pp. 183-192; PLEGUEZUELO, Alfonso: "Nuevas obras del pintor Domingo Martínez", en In Sapientia Libertas. Escritos en homenaje al profesor Alfonso E. Pérez Sánchez. Madrid-Sevilla, 2007, pp. 571-580; VALDIVIESO GONZÁLEZ, Enrique: "Pintura mural del siglo XVIII en Sevilla", en Pintura mural sevillana del siglo XVIII. Sevilla, 2016, pp. 16 et al.; y VALDIVIESO, Enrique: La escuela de Murillo. Aportaciones al conocimiento de sus discípulos y seguidores. Sevilla, 2018, pp. 299-318.

${ }^{26}$ PÉREZ SÁNCHEZ, Alfonso E.: "Dibujos de Domingo Martínez", en Domingo Martínez en la estela..., op. cit., pp. 42-43.

${ }^{27}$ RODRÍGUEZ, Inmaculada: "Virgen con el Niño", en Domingo Martínez en la estela..., op. cit., pp. 172-173.

${ }^{28}$ Reproducidas en VALDIVIESO, Enrique: Murillo. Catálogo razonado de pinturas. Madrid, 2010, pp. 302, 482 y 483. 
temperamento expresivo, el gusto refinado y los estilemas presentes en la época de plenitud de Domingo Martínez, en la década de 1740, cuando sería factible fechar este óleo, al socaire de los paralelismos que también pueden esgrimirse entre los amables rasgos faciales de esta Virgen de Belén (Figura 5) con los de la Divina Pastora (Figura 6) del convento de las trinitarias de San Ildefonso de Madrid ${ }^{29}$, o entre los de su rubicundo infante y el de la Sagrada Familia con Niño Jesús pasionario del comercio de arte ${ }^{30}$, por no prodigar excesivamente los ejemplos de otras pinturas coetáneas documentadas o firmemente atribuidas a este pintor que podrían traerse a colación.

Fecha de recepción: 30 de octubre de 2018

Fecha de aceptación: 5 de febrero de 2019

${ }^{29}$ QUESADA VALERA, José María: "Divina Pastora", en Clausuras. Tesoros artísticos en los conventos y monasterios madrileños. Madrid, 2007, pp. 183-185.

30 PLEGUEZUELO, Alfonso: "Nuevas obras...", op. cit., p. 571. 


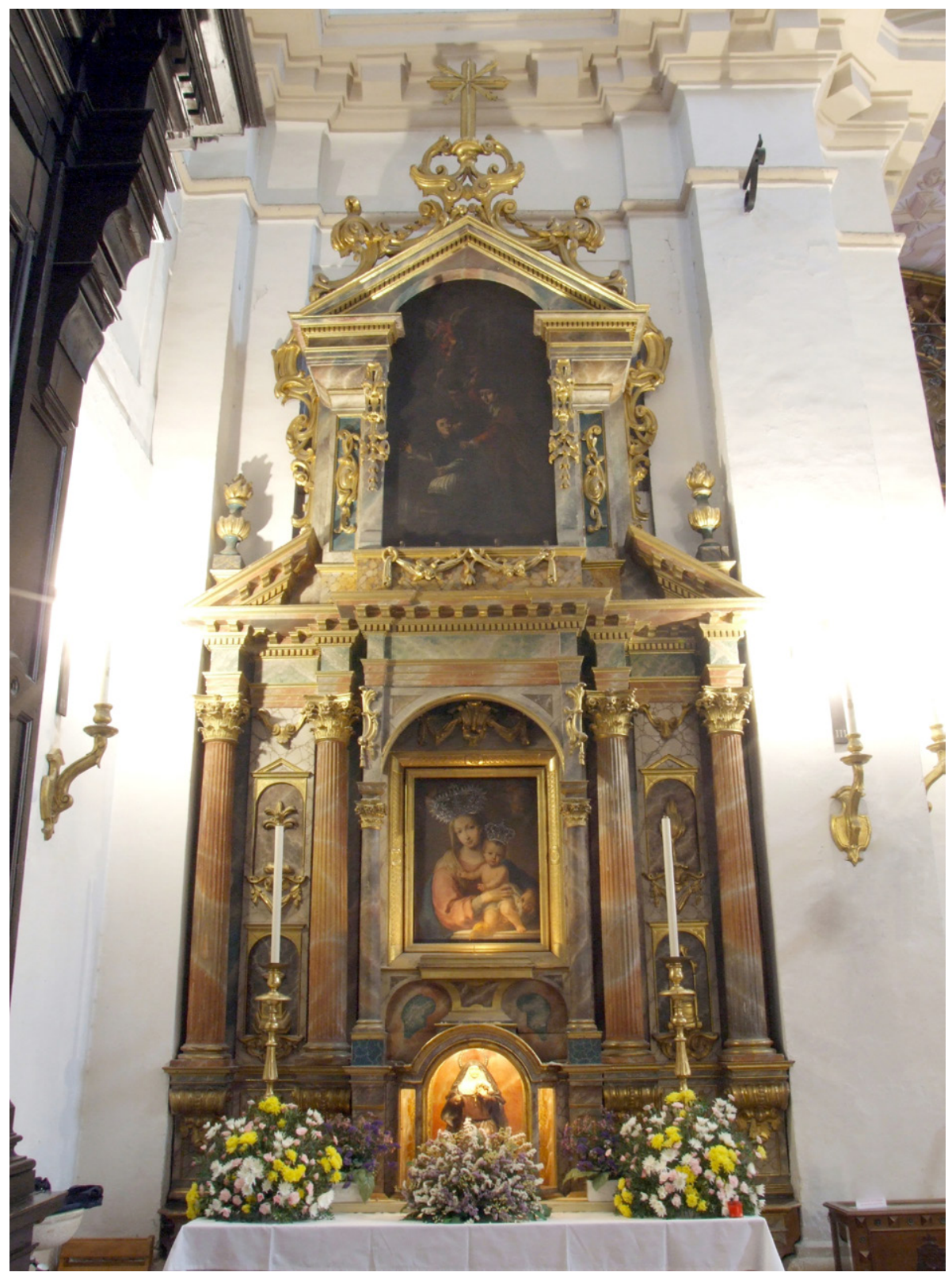

Figura 1. Retablo de la Virgen de Belén, fines del siglo XVIII, iglesia de Nuestra Señora de la Paz, Sevilla. 


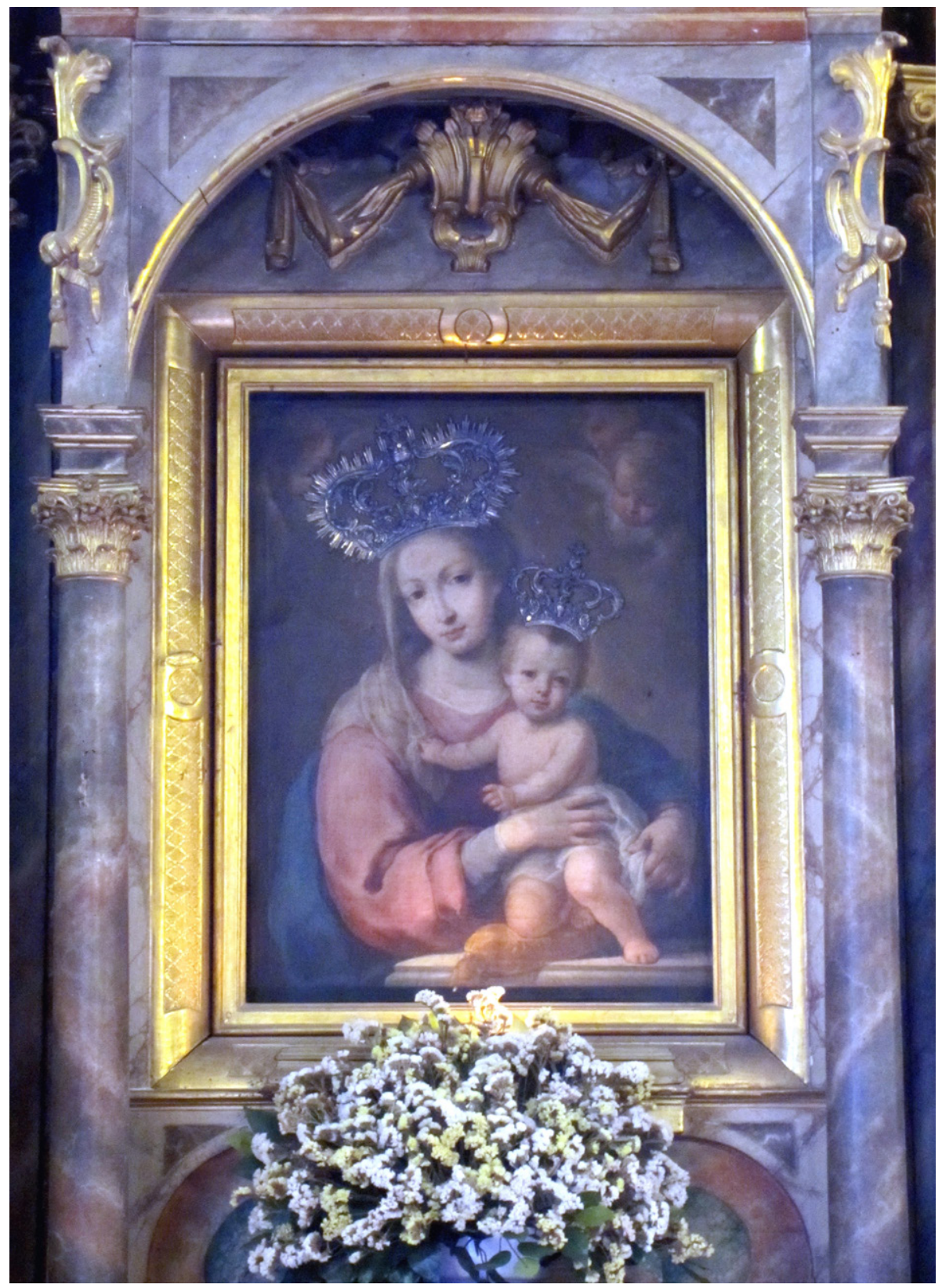

Figura 2. Retablo de la Virgen de Belén (detalle de la calle central), iglesia de Nuestra Señora de la Paz, Sevilla. 


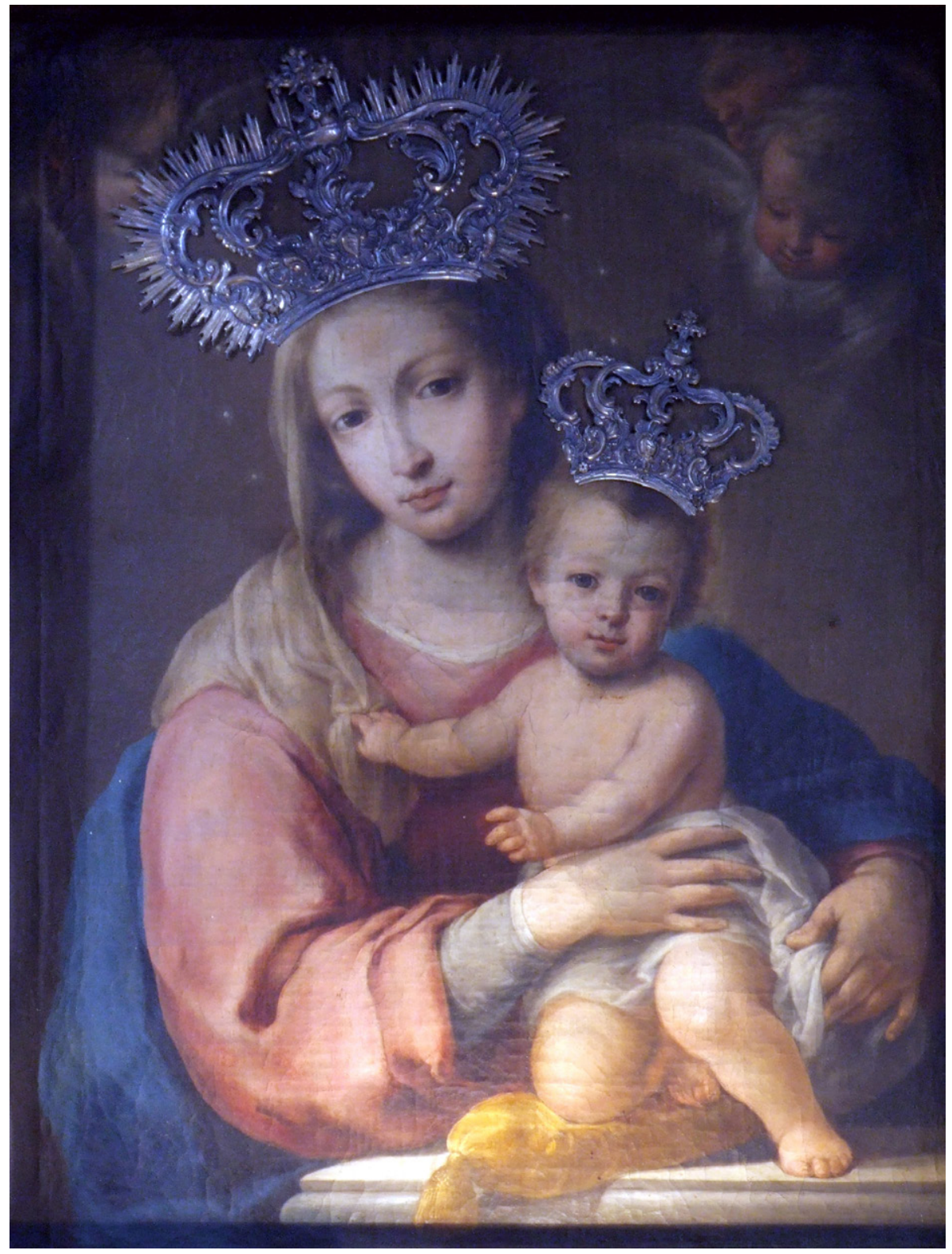

Figura 3. Domingo Martínez, Virgen de Belén, década de 1740, iglesia de Nuestra Señora de la Paz, Sevilla. 


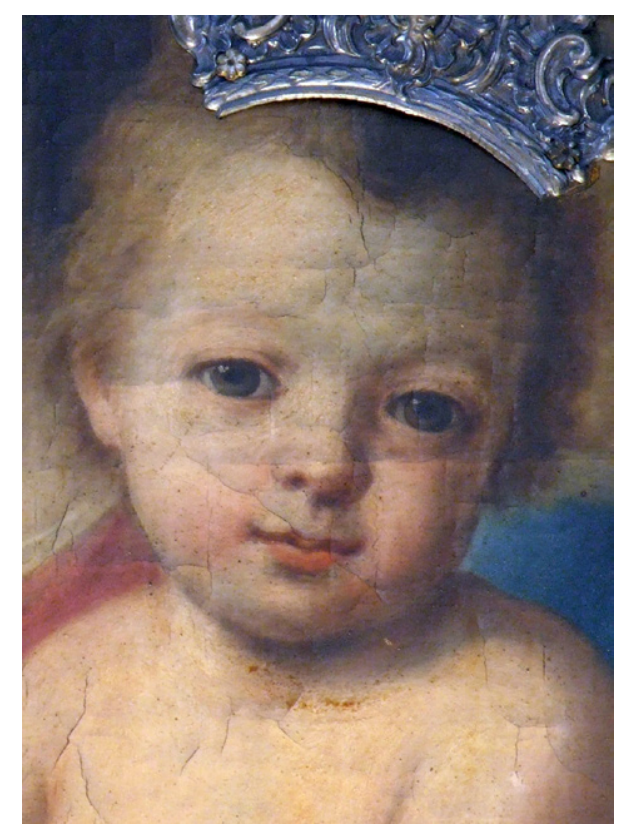

Figura 4. Domingo Martínez, Virgen de Belén (detalle del Niño Jesús), década de 1740, iglesia de Nuestra Señora de la Paz, Sevilla.

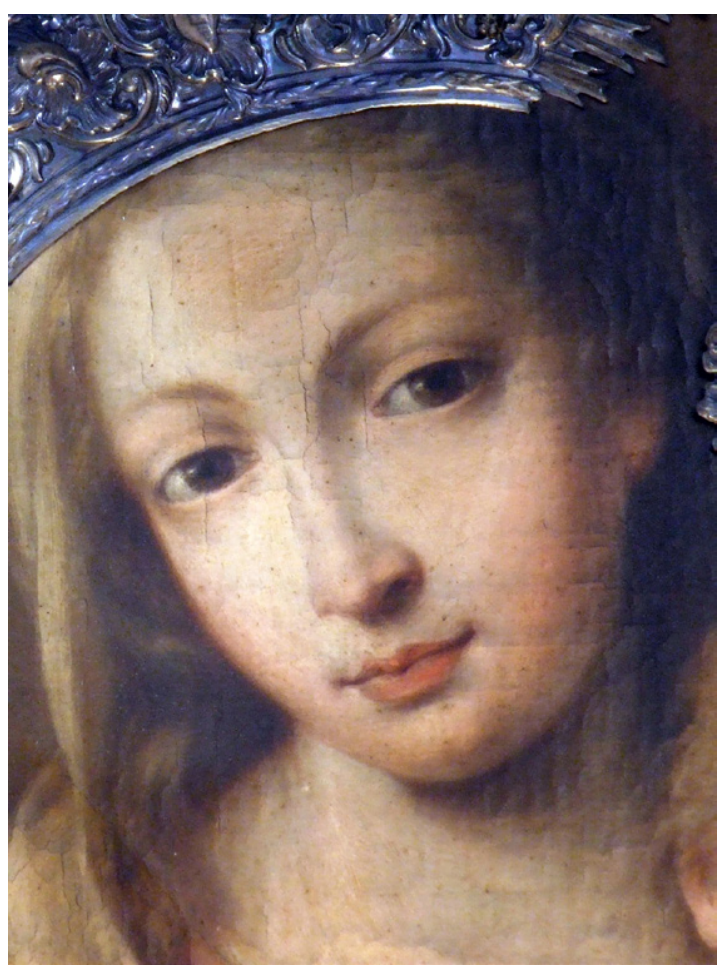

Figura 5. Domingo Martínez, Virgen de Belén (detalle del rostro de María), década de 1740, iglesia de Nuestra Señora de la Paz, Sevilla. 


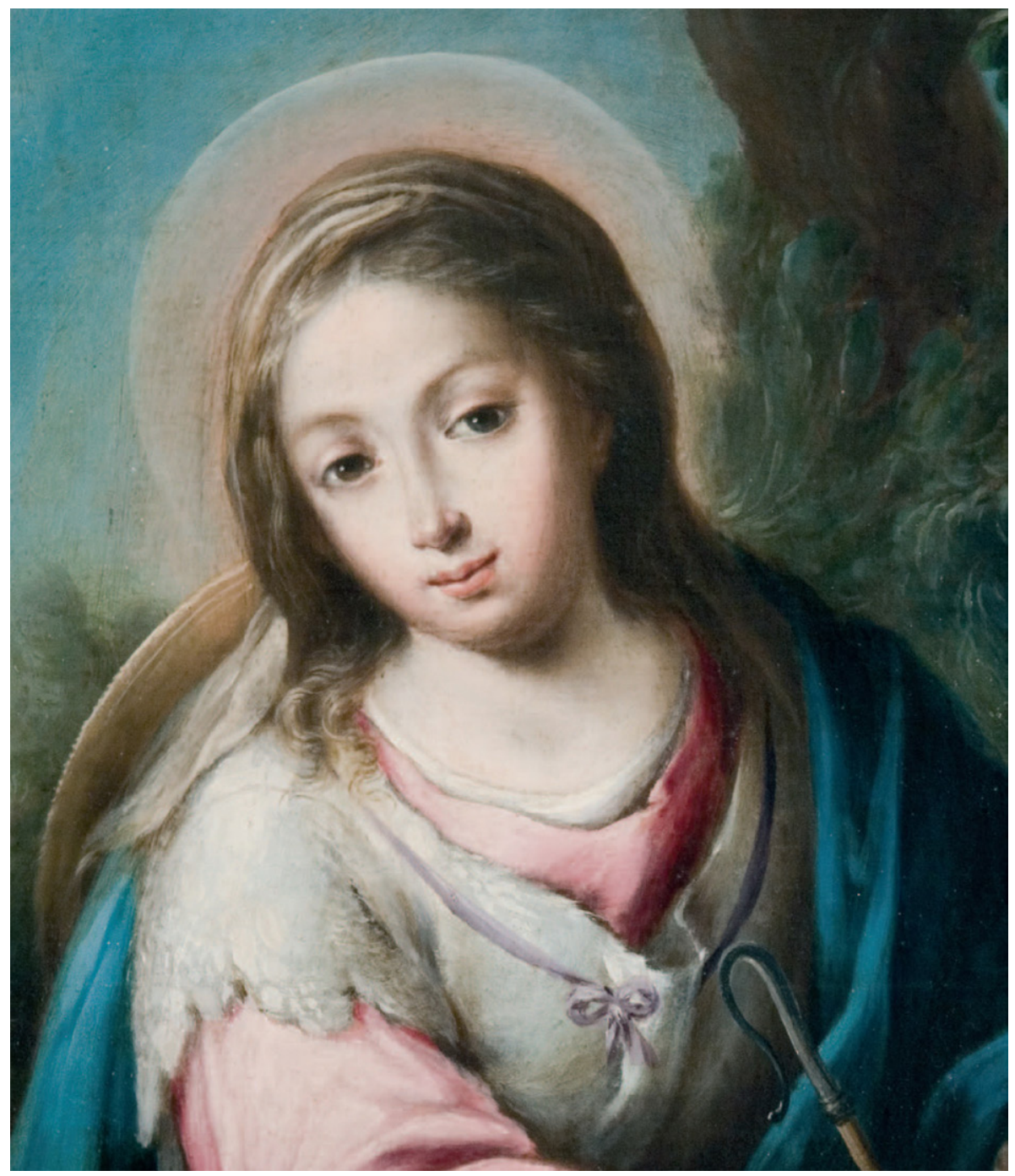

Figura 6. Domingo Martínez, Divina Pastora (detalle), década de 1730, monasterio de trinitarias de San Ildefonso, Madrid. 